\title{
Performance of non-invasive prenatal testing for trisomies 21 and 18 in twin pregnancies
}

\author{
Jiexia Yang ${ }^{1,2 \dagger}$, Yiming Qi ${ }^{1,2 \dagger}$, Yaping Hou ${ }^{1,2}$, Fangfang Guo ${ }^{1,2}$, Haishan Peng ${ }^{1,2}$, Dongmei Wang ${ }^{1,2}$, O. Y. Haoxin ${ }^{1,2}$, \\ Yixia Wang ${ }^{1,2}$, Huajie Huang ${ }^{1,2}$ and Aihua Yin ${ }^{1,2^{*}}$
}

\begin{abstract}
Background: Cell-free fetal DNA in maternal plasma represents a source of fetal genetic material that can be sampled noninvasively. There are ample studies confirming the accuracy of NIPT in singleton pregnancies, but there is still relatively little studies demonstrate the feasibility and clinical application of a NIPT for fetal aneuploidy screening in twin pregnancies.

Results: In this study, we have finished 432 twin pregnancies screening by NIPT. There were 4 double chorionic dichorionic diamniotic (DCDA) cases of true positive NIPT results, including 1 of T18 and 3 of T21, and 1 monochorionic diamniotic (MCDA) cases of true positive NIPT results, including 1of T21. The combined falsepositive frequency for trisomies 21, 18 was $0 \%$. Furthermore, there were 2 cases of false positive NIPT results, including 1 of T7 and 1 of sex chromosome aneuploidy. There was no false negative case, which gave a combined sensitivity and specificity of 100 and $99.53 \%$ respectively.

Conclusion: Our study demonstrated NIPT performed well in the detection of trisomy 21 in twin pregnancy. It is feasible and clinical applicable of NIPT for fetal aneuploidy screening in twin pregnancies. But, it needs a large number of clinical samples to demonstrate the applicability of other chromosomal abnormalities besides trisomies 21 and 18 in both singleton pregnancies and twin pregnancies.
\end{abstract}

Keywords: Non-invasive prenatal testing (NIPT), Twin pregnancy, Trisomy 21, Assisted reproductive techniques (ART), Amniocentesis

\section{Background}

Non-invasive prenatal testing for aneuploidy by cell-free DNA (cfDNA) has been available clinically for over several years. In singleton pregnancies, cfDNA analysis of maternal blood provides effective screening for trisomies 21,18 and 13 with respective detection rates of about 99, 97 and 92\%, at a combined false-positive rate (FPR) of 0.4 [1]. Such high performance of screening has been reported for both high-risk pregnancies and in the general population [2-4].

\footnotetext{
* Correspondence: yinaiwa@126.com

†jiexia Yang and Yiming Qi contributed equally to this work.

${ }^{1}$ Prenatal Diagnosis Centre, Guangdong Women and Children Hospital, Guangzhou 511400, Guangdong, China

${ }^{2}$ Maternal and Children Metabolic-Genetic Key Laboratory, Guangdong

Women and Children Hospital, Guangzhou 511400, Guangdong, China
}

However, multiple births now account for 3\% of all births worldwide $[5,6]$. The rate of twin birth increased by more than $75 \%$ in the United States from 1980 to 2009 [7]. Similar trends have been observed in Western Europe and other countries [5]. Traditionally, both the risk for aneuploidies and the risk of miscarriage from invasive testing are higher in twin pregnancies than in singletons $[8,9]$. With a high proportion of twin births thought to originate in women undergoing assisted reproductive technology (ART), the use of non-invasive prenatal testing (NIPT) to screen for fetal aneuploidy is especially desirable. Preliminary data have suggested that NIPT is a feasible test option for twin gestations [10, 11]. Currently, due to the lack of data in twins, professional societies have called for more researches on NIPT performance in twin gestations [12-14].

(c) The Author(s). 2018 Open Access This article is distributed under the terms of the Creative Commons Attribution 4.0 International License (http://creativecommons.org/licenses/by/4.0/), which permits unrestricted use, distribution, and reproduction in any medium, provided you give appropriate credit to the original author(s) and the source, provide a link to the Creative Commons license, and indicate if changes were made. The Creative Commons Public Domain Dedication waiver (http://creativecommons.org/publicdomain/zero/1.0/) applies to the data made available in this article, unless otherwise stated. 
However, in twin pregnancies cfDNA testing is more complex than in singleton pregnancies because if a trisomy occurs in a dizygous twin pregnancy, usually only one of the fetuses is affected, and the contribution of cfDNA of the two fetuses into the maternal circulation can vary by nearly two-fold $[15,16]$. If the fetal fraction of the affected fetus is below the threshold of $4 \%$ necessary for successful cfDNA analysis, but there is a high contribution from the normal cotwin. Consequently, the complexity of the fetal fraction in twin gestations has raised concerns about a potentially increased false-negative rate of NIPT in twin gestations. It is then crucial that each twin contributes enough cell-free fetal DNA (cffDNA) to discriminate between aneuploid and euploid pregnancies.

Professional societies and others have called for more studies on NIPT performance in twin gestations [13, 14], and an increasing number of clinical data are showing that the sensitivity and specificity for the detection of fetal trisomy 21 by NIPT in twin pregnancies-monozygous as well as dizygous-are comparable to those in singleton pregnancies [16, 17].

Cell-free DNA testing in twin pregnancies is more complex, because the 2 fetuses could be either monozygotic or dizygotic, in which case only 1 fetus is likely to have aneuploidy when present. In this study, we have finished 432 twin pregnancies screening by NIPT. There were 5 cases of true positive NIPT results, in which only 1 fetus was aneuploidy of the 5 cases. At last, we discussed the feasibility and clinical application of NIPT for fetal aneuploidy screening in twin pregnancies.

\section{Methods}

\section{Samples collection}

In this study, 432 twin pregnancies underwent screening for trisomies 21, 18 and 13 by cfDNA testing between January 2015 and December 2016. All patients received detailed pretest counseling and provided written informed consent for the test.

\section{Maternal plasma DNA sequencing}

Blood samples from women pregnant with twin gestations have been collected for NIPT. From each pregnant woman, $5 \mathrm{~mL}$ of peripheral blood was obtained in an ethylene diamine tetraacetic acid-anticoagulated tube before invasive procedures, and plasma was separated within $8 \mathrm{~h}$ following a double-centrifugation protocol. All subsequent procedures, including cell-free DNA isolation, library construction, and sequencing, were performed according to instructions of JingXin Fetal Chromosome Aneuploidy (T21, T18, T13) Testing Kits (CFDA registration permit No. 0153400300).
Bioinformatics analysis for the detection of trisomies 21 and 18

Based on our previous study, we developed a technique that uses the read length to estimate the concentration of fetal cfDNA in maternal plasma by sequencing [18]. The fetal DNA concentration was calculated as a quality control, as described in Yin's paper [18]. Combined GC-correction and Z-score testing methods were used to identify fetal autosomal aneuploidy for trisomy as described in Liao's paper [19]. Z score range from -3 to 3 was considered to indicate a low risk for a trisomy chromosome [20], and if $\mathrm{Z}$ score were $>3$, the sample was in the high-risk zone.

\section{Karyotyping analysis}

Invasive sampling was performed for high risk cases. The metaphase chromosome Gbanding karyotyping was performed at a level of 320 to 400 bands. The results of karyotyping were used as the gold standard to calculate the sensitivity and specificity of sequencing-based NIPT. In this study, 95\% confidence intervals were evaluated on the basis of standard normal distribution.

\section{Results}

\section{Study population}

In this study, there were 432 twin pregnancies underwent screening for NIPT. Basic characteristics of the study population are shown in Table 1. 58.5 and $77.9 \%$ of pregnant women were younger than 35 years old. There were 337 pregnancies of double chorionic dichorionic diamniotic (DCDA), and there were 247 pregnancies ofartificial reproductive technology (ART) of those 337 cases. There were 95 pregnancies monochorionic diamniotic (MCDA), and there were 92 pregnancies of ART of those 95 cases.

Table 1 Demographic characteristic of pregnant women undergoing NIPT

\begin{tabular}{lll}
\hline Characteristic & $\operatorname{DCDA}(n=337)$ & $\operatorname{MCDA}(n=95)$ \\
\hline $\begin{array}{l}\text { Maternal age (years) } \\
<35(\mathrm{n}, \%)\end{array}$ & $197(58.5)$ & $74(77.9)$ \\
$>=35(\mathrm{n}, \%)$ & $140(41.5)$ & $21(22.1)$ \\
Gestational age NIPT & & \\
9-13 week(n, \%) & $47(13.9)$ & $14(14.7)$ \\
14-27 week(n, \%) & $278(82.5)$ & $72(75.9)$ \\
$>=28$ week(n, \%) & $12(3.6)$ & $9(9.5)$ \\
Type of pregnancy & & \\
Artificial reproductive technology & $247(73.3)$ & $92(96.8)$ \\
Natural pregnancy & $90(26.7)$ & $3(3.2)$ \\
\hline
\end{tabular}

DCDA Dichorionic diamniotic, MCDA Monochorionic diamniotic 


\section{NIPT positive of fetal trisomies 21 and 18}

There were 5 of true positive cases in the 432 twin pregnancies, including 1 case of trisomies 18 and 4 cases of trisomies 21. Clinical details of the 5 cases were summarized in the Table 2. Maternal age of case 1 was 31, and all of the T21 cases were advanced maternal age. The gestational age of the 3 cases was from 16 to 19 weeks, and all of the cases were pregnancy with artificial reproductive technology except case 5 . There were 2 of false positive cases in the 432 twin pregnancies, including 1 case of T7 and 1 case of sex chromosomal aneuploidy. Table 3 summarized the clinical information of these 2 false positives cases. Both cases were pregnancies with artificial reproductive technology. Fetal fractions of the 5 true positives cases were 9.0, 7.5, 6.1, 30.6 and 21.2, and false positive cases were 7.6 and 19.7. The $\mathrm{Z}$ scores were $>3$ of each case (Tables 2, 3). All of the 7 cases were identified as high risk sample, which were suggested to take invasive test for further diagnosis.

\section{Karyotyping results}

Invasive sampling was performed for high risk cases, and karyotyping results were obtained in those 6 cases. Cases 7 refused to perform prenatal diagnosis. One of the fetuses of case 1 was trisomies 18, and the other fetus was normal. One of the fetuses of case 2 , case 3 , case 4 and case 5 was trisomies 21, and the other was normal. NIPT results showed the 5 cases were high risk, which was consistent with karyotyping results. In addition, karyotyping of case 6 was normal, which was discordance with NIPT result. Prenatal diagnosis proved case 6 was false positive of T7 (Fig. 1, Table 2 and Table 3).

\section{Follow-up investigations}

Fetal reduction operation was performed in those true positive cases of trisomy 21 and trisomy 18. Pregnant woman of case 7 refused prenatal diagnosis, and decided to continue the pregnancy. At last, two normal fetuses were delivered. The remaining 425 cases were classified as negative. Pregnancy outcome was available in 393 cases, whereas the remaining 32 cases were lost to follow up. On the one hand, for DCDA cases, there were 301 pregnancies with normal fetus and a fetus of intrauterine death, and one of the twins induced labor because of an abnormal heart showed by ultrasonography. In addition, there are 3 cases of spontaneous abortion pregnancy, and 3 of termination of pregnancy. On the other hand, for MCDA cases, there were 82 pregnancies with normal fetus, and a fetus of intrauterine death. In addition, one fetus died after birth.

\section{NIPT performance}

Accuracy is a very important parameter of NIPT, hence in this population of 432 twin pregnancies, karyotype or live birth feedbacks were obtained to compare the false negative and false positive results of the NIPT predicted results. Further calculation of NIPT sensitivity and specificity was based on this subgroup of the population with outcome data available. In total, we received 373 feedbacks. There were 5 true positive cases, 2 false positive cases and none false negative case, resulting the total sensitivity and specificity were 100 and $99.53 \%$ respectively.

\section{Discussion}

Although NIPT performance has been extensively studied in singleton pregnancies, its efficacy is rarely reported in twin pregnancies. Here, we demonstrate the feasibility and clinical application of NIPT for fetal aneuploidy screening in twin pregnancies. In this study, we have finished 432 twin pregnancies screening by NIPT. There were 4 DCDA cases of true positive NIPT results, including 1 of T18 and 3 of T21, and 1 MCDA cases of true positive NIPT results, including 1of T21, and there were 2 cases of false positive NIPT results, including 1 of T7 and 1 of sex chromosome aneuploidy. There was no false negative case, which gave a combined sensitivity and specificity of 100 and $99.53 \%$ respectively.

Conventional serum screening approaches have relatively high false-positive rates [21] in twin pregnancies and often cannot provide a result for trisomies 18 or 13 when compared with singletons. Therefore, there is a need for an accurate non-invasive method for fetal aneuploidy detection of trisomies 21, 18 and 13 in twin pregnancies. Cell-free fetal DNA in maternal plasma represents a source of fetal genetic material that can be sampled noninvasively. There are ample studies

Table 2 Clinical details of the 5 cases with fetal trisomies 18 and 21

\begin{tabular}{|c|c|c|c|c|c|c|c|c|}
\hline Placentation & Case & Maternal age & Gestational age & Conception & Fetal fraction & $\mathrm{BMI}$ & NIPT Result & Karyotyping \\
\hline \multirow[t]{4}{*}{ DCDA } & Case 1 & 31 & 19 & ART & 9 & 25 & $\mathrm{~T} 18$ & Normal/T18 \\
\hline & Case 2 & 37 & 18 & ART & 7.5 & 22 & $\mathrm{~T} 21$ & Normal/T21 \\
\hline & Case 3 & 35 & 16 & ART & 21.2 & 23 & $\mathrm{~T} 21$ & Normal/T21 \\
\hline & Case 4 & 36 & 16 & ART & 30.6 & 22 & $\mathrm{~T} 21$ & Normal/T21 \\
\hline MCDA & Case 5 & 37 & 16 & NP & 6.1 & 27 & T21 & Normal/T21 \\
\hline
\end{tabular}

DCDA Dichorionic diamniotic, MCDA Monochorionic diamniotic, ART Artificial reproductive technology, NP Natural pregnancy 
Table 3 Clinical details of false positive NIPT results

\begin{tabular}{lllllllll}
\hline Placentation & Case & Maternal age & Gestational age & Conception & Fetal fraction & BMI & NIPT Result & Karyotyping \\
\hline DCDA & Case 6 & 26 & 14 & ART & 7.6 & 27 & T7/ Normal & Normal \\
& Case 7 & 24 & 18 & ART & 19.7 & 20 & 47, XXX & NA
\end{tabular}

DCDA Dichorionic diamniotic, MCDA Monochorionic diamniotic, ART Artificial reproductive technology, NP Natural pregnancy. NA No abnormalities

confirming the accuracy of NIPT in singleton pregnancies, but there is still relatively little studies demonstrate the feasibility and clinical application of a NIPT for fetal aneuploidy screening in twin pregnancies. Mar Gil et al. demonstrated cfDNA testing in twins was feasible but the reporting rate of results is lower than in singletons due to a lower fetal fraction [10]. Bevilacqua et al. demonstrated in twin pregnancies screening by cfDNA testing is feasible, but the failure rate is higher and detection rate may be lower than in singletons [11]. The last study of Fosler's demonstrated NIPT performed well in the detection of trisomy 21 in twin pregnancy, NIPT for fetal Down syndrome in twin pregnancy is likely to be as accurate as in singleton pregnancies [22]. Prenatal screening is important to ART pregnancies, because couples opting for ART and the conceived fetuses have higher rate of chromosome abnormalities comparing to general population [23-25]. Furthermore, it is a particularly desirable option for ART patients for whom fear of procedure-related loss is heightened due to difficulties achieving pregnancy.

Twins can be either identical or fraternal. Therefore, it is of clinical importance to be able to distinguish the different types of twins for prenatal diagnosis. In our study, only one of the fetuses was affected and another was normal of all the true positive cases. Over half of the cases in DCDA group were ART pregnancies, and the proportion of ART pregnancies in MCDA group reached 96\%. In DCDA group, our NIPT identified 4 trisomic twin pregnancies with 2 false positive and no negative. In group MCDA, evaluation of the 95 reported clinical twin samples revealed 1 with aneuploidy detected or suspected, no reported false positive in the aneuploidy detected sample and no reported false negative. Monochorionic twins are generally considered to be genetically identical, thus presenting a difficult counseling scenario when they have discordant anomalies [26]. Monozygotic twins with discordant prenatal presentations are a rare but known phenomenon with multiple potential explanations. The formation mechanism of MCDA that one fetuses has normal karyotype and another with trisomy may be as follows: (1) In meiosis, the chromosomes do not separate to form a gametes of 24 chromosomes, which combine with a normal gamete to produce a trisomic zygote, resulting in the formation of a trisomy rescue after the formation of a twin, and the random loss of an extra chromosome. A third of the fetus may be a single parent diploid fetus, the other child

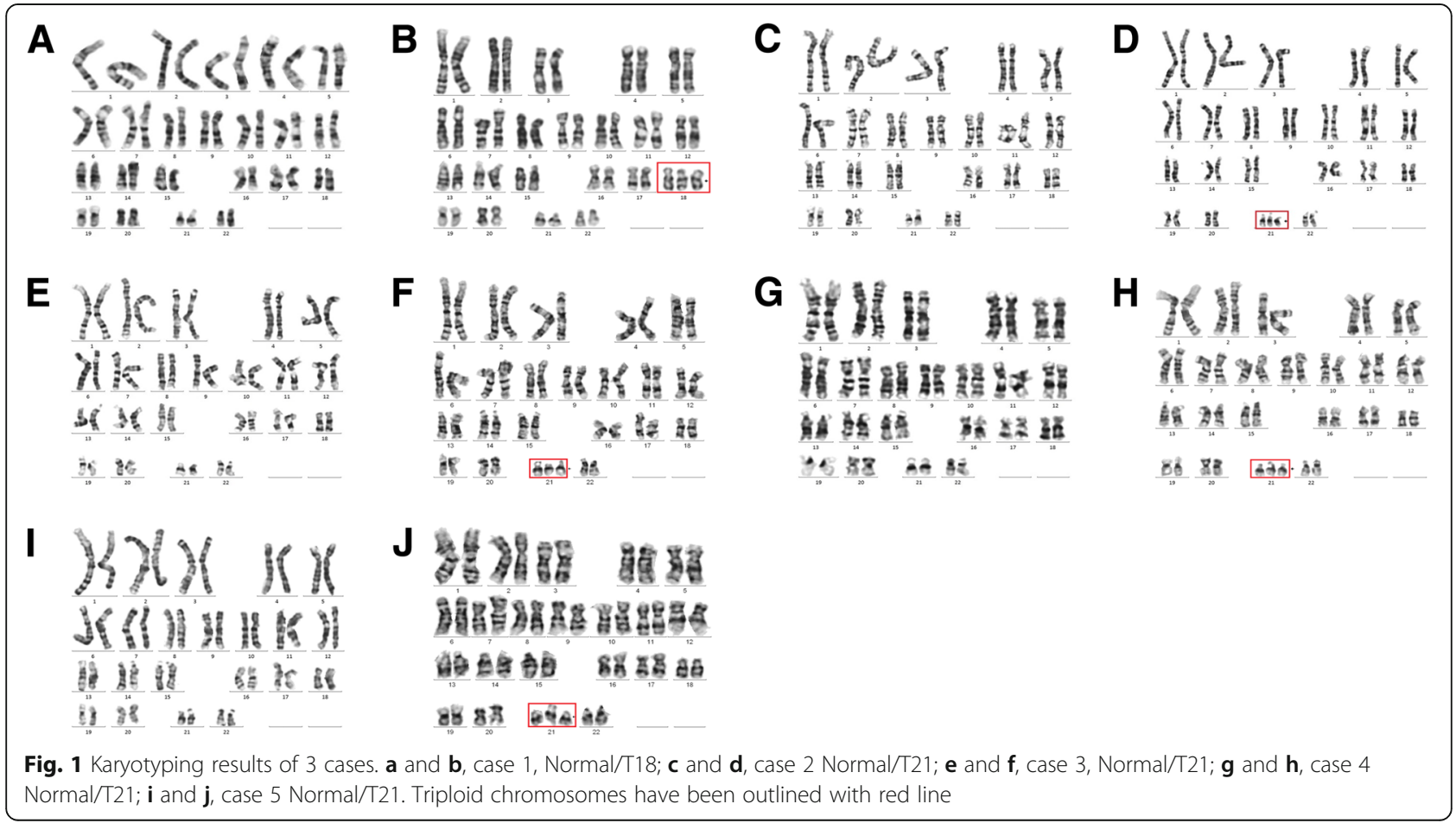


did not have trisomy to save itself, and continues to develop into trisomy; (2) The fertilized egg is a normal diploid. After the formation of the twin embryo, the chromosome is not separated during mitosis. Two cell lines, trisomy and monomeric are formed. The monomeric cell line dies because of its mortality, and the trisomy cell line develops into a trisomy; the other one continues to develop into a normal fetus.

Our study had finished 432 twin pregnancies screening by NIPT, there was no false negative case and the combined false-positive frequency for trisomies 21, 18 was $0 \%$. But we had found 2 false positive cases, including 1 of T7 and 1 of sex chromosome aneuploidy. Case 6 had performed amniocentesis to diagnose, and amniocentesis confirmed karyotype of the twins was normal. Pregnant women of case 7 refused to take interventional prenatal diagnosis, she chose ultrasound examination regularly and ultrasound showed no abnormalities. At last, she delivered normal twin babies. False positives for NIPT can occur for a number of reasons, including maternal mosaicism [27, 28], maternal cancer [29], a demised twin $[30,31]$, or most commonly, confined placental mosaicism [32, 33]. NIPT reflects the genomic constitution of the placenta, not of the fetus itself and feto-placental discrepancy can cause false-positive (trisomy) NIPT results [34]. Chromosomal loss in trisomy (trisomy rescue) to generate a disomic fetus can cause confined placental mosaicism and/or feto/placental mosaicism. After trisomy rescue event, there is a risk of fetal uniparental disomy (UPD) [35], which is a strength of NIPT. In this study, we speculated that UPD may be a cause of false positive T7. UPD could lead to clinically significant conditions by producing either homozygosity for recessive mutations or aberrant patterns of imprinting, but UPD cannot be detected by conventional karyotyping, nor can it be detected by the current method of NIPT, so we recommend the baby to do more testing. Meanwhile, it needs a large number of clinical samples to demonstrate the applicability of NIPT in the detection of other chromosomal abnormalities besides trisomies 21, 18 and 13 in both singleton pregnancies and twin pregnancies.

\section{Conclusion}

It may be argued that NIPT is not good enough because if it is positive, we still do not know which of the two fetuses is affected. But, for the far majority of cases in which both fetuses are normal, the NIPT will enable the couple to avoid any invasive test, because of the high sensitivity and specificity. NIPT enables the selection of almost only the affected pregnancies for invasive test. Recently, there were several publications suggested the possible for Non-invasive determination of zygosity [15, 36], and I believe it is possible to determine which of the two fetuses is affected in a screened positive case by NIPT in the near future.

\section{Abbreviations}

ART: Assisted reproductive technology; cfDNA: Cell free DNA; cffDNA: Cellfree fetal DNA; DCDA: Double chorionic dichorionic diamniotic; GA: Gestational age; MCDA: Monochorionic diamniotic; NIPT: Non-invasive prenatal testing; NP: Natural pregnancy; T18: trisomy 18; T21: trisomy 21

\section{Acknowledgements}

Thanks to the CapitalBio Genomics Co., Ltd. for data analysis and writing help.

\section{Funding}

National Key Research and Development Program of China, 2016YFC1000700, 2016YFC1000703.

Guangdong Medical Science and Technology Research Project, 2016118171659322.

\section{Availability of data and materials}

The datasets used and/or analyzed during the current study are available from the corresponding author on reasonable request.

\section{Authors' contributions}

All authors have materially participated in the study and manuscript preparation. JY and YQ carried out all the molecular genetic analysis, and paticipated in the design of the work; FG and YH collected all clininal data and participated in conceiving the work; DW and $\mathrm{HO}$ participated in conceiving the work, and revising the manuscript. AY designed the work, drafted and revised the manuscript. All authors have approved the final article.

\section{Ethics approval and consent to participate}

This study was performed with the approval of Medical Ethics Committee of Guangdong Women and Children Hospital, and written informed consent was obtained from the patient.

\section{Consent for publication}

The patients in this research have provided their consent for publication.

\section{Competing interests}

The authors declare that they have no competing interests.

\section{Publisher's Note}

Springer Nature remains neutral with regard to jurisdictional claims in published maps and institutional affiliations.

Received: 5 March 2018 Accepted: 23 July 2018

Published online: 22 August 2018

\section{References}

1. Gil MM, Akolekar R, Quezada MS, et al. Analysis of cell-free DNA in maternal blood in screening for aneuploidies: meta-analysis. Ultrasound Obstet Gynecol. 2014;35(3):156.

2. Nicolaides $\mathrm{KH}$, Syngelaki A, Ashoor G, et al. Noninvasive prenatal testing for fetal trisomies in a routinely screened first-trimester population. Am J Obstet Gynecol. 2012;207(5):374-e371.

3. Song Y, Liu C, Qi H, et al. Noninvasive prenatal testing of fetal aneuploidies by massively parallel sequencing in a prospective Chinese population. Prenat Diagn. 2013;33(7):700.

4. Liao C, Zhengfeng $X$, Zhang K. DNA sequencing versus standard prenatal aneuploidy screening. N Engl J Med. 2014;371(6):578

5. Martin JA, Hamilton BE. Osterman MJ three decades of twin births in the United States, 1980-2009. Nchs Data Brief. 2012;80:1.

6. Pison G. D'Addato AV frequency of twin births in developed countries. Twin Res Hum Genet. 2006:9(2):250.

7. Collins J. Global epidemiology of multiple birth. Reprod Biomed Online. 2007;15(Suppl 3):45

8. Hansen M, Kurinczuk JJ, Milne E, et al. Assisted reproductive technology and birth defects: a systematic review and meta-analysis. Hum Reprod Update. 1900;19(4):330-53.

9. Kähler C, Gembruch U, Heling KS, et al. DEGUM guidelines for amniocentesis and chorionic villus sampling. Ultraschall Med. 2013;34(5):435-40. 
10. del Mar GM, Quezada MS, Bregant B, et al. Cell-free DNA analysis for trisomy risk assessment in first-trimester twin pregnancies. Fetal Diagn Ther. 2014;35(3):204-11.

11. Bevilacqua $\mathrm{E}$, Gil MM, Nicolaides $\mathrm{KH}$, et al. Performance of screening for aneuploidies by cell-free DNA analysis of maternal blood in twin pregnancies. Ultrasound Obstet Gynecol. 2015:45(1):61-6.

12. Wilson RD. Committee opinion no. 640: cell-free DNA screening for fetal aneuploidy. Obstet Gynecol. 2015;126(3):31-7.

13. Gil MM, Accurti $V$, Santacruz B, et al. Analysis of cell-free DNA in maternal blood in screening for aneuploidies: updated meta-analysis. Ultrasound Obstet Gynecol. 2017:50(3):302-14.

14. Committee on Practice Bulletins-Obstetrics CoG. Medicine tSfM-F Practice Bulletin No. 163: Screening for Fetal Aneuploidy. Obstet Gynecol. 2016; 127(5):e123.

15. Qu JZ, Leung TY, Jiang $P$, et al. Noninvasive prenatal determination of twin zygosity by maternal plasma DNA analysis. Clin Chem. 2013;59(2):427.

16. Leung TY, Qu JZ, Liao GJ, et al. Noninvasive twin zygosity assessment and aneuploidy detection by maternal plasma DNA sequencing. Prenat Diagn. 2013;33(7):675

17. Canick JA, Kloza EM, Lambertmesserlian GM, et al. DNA sequencing of maternal plasma to identify Down syndrome and other trisomies in multiple gestations. Prenat Diagn. 2012;32(8):730-4.

18. Ai-Hua Y, Chun-Fang P, Xin Z, et al. Noninvasive detection of fetal subchromosomal abnormalities by semiconductor sequencing of maternal plasma DNA. Proc Natl Acad Sci U S A. 2015;112(47):14670.

19. Liao $C$, Yin $A H$, Peng $C F$, et al. Noninvasive prenatal diagnosis of common aneuploidies by semiconductor sequencing. Proc Natl Acad Sci U S A. 2014;111(20):7415-20.

20. Chiu RW, Akolekar R, Zheng YW, et al. Non-invasive prenatal assessment of trisomy 21 by multiplexed maternal plasma DNA sequencing: large scale validity study. Bmj. 2011;342(7790):c7401.

21. Audibert F, Gagnon A. No. 262-prenatal screening for and diagnosis of aneuploidy in twin pregnancies. J Obstet Gynaecol Can. 2017;39(9):e347-61.

22. Fosler $L$, Winters $P$, Jones KW, et al. Aneuploidy screening by non-invasive prenatal testing in twin pregnancy. Ultrasound Obstet Gynecol. 2017; 49(4):470-7.

23. Gjerris AC, Loft A, Pinborg A, et al. Prenatal testing among women pregnant after assisted reproductive techniques in Denmark 1995-2000: a national cohort study. Hum Reprod. 2008;23(7):1545-52.

24. Gjerris AC, Loft A, Pinborg A, et al. First-trimester screening markers are altered in pregnancies conceived after IVF/ICSI. Ultrasound Obstet Gynecol. 2009;33(1):8-17.

25. Radojcić Badovinac A, Buretić-Tomljanović A, Starcević N, et al. Chromosome studies in patients with defective reproductive success. Am J Reprod Immunol. 2015;44(5):279-83.

26. Rock KR, Millard S, Seravalli V, et al. Discordant anomalies and karyotypes in a monochorionic twin pregnancy: a call for comprehensive genetics evaluation. Ultrasound Obstet Gynecol. 2017;49(4):544-45.

27. Yao $\mathrm{H}$, Zhang $\mathrm{L}$, Zhang $\mathrm{H}$, et al. Noninvasive prenatal genetic testing for fetal aneuploidy detects maternal trisomy X. Prenat Diagn. 2012; 32(11):1114-6

28. Wang JC, Sahoo T, Schonberg S, et al. Discordant noninvasive prenatal testing and cytogenetic results: a study of 109 consecutive cases. Genet Med. 2015;17(3):234-6.

29. Bianchi DW, Chudova D, Sehnert AJ, et al. Noninvasive prenatal testing and incidental detection of occult maternal malignancies. J Am Med Assoc. 2015;314(2):162

30. Futch T, Spinosa J, Bhatt $\mathrm{S}$, et al. Initial clinical laboratory experience in noninvasive prenatal testing for fetal aneuploidy from maternal plasma DNA samples. Prenat Diagn. 2013;33(6):569-74.

31. Curnow KJ, Wilkinshaug $L$, Ryan $A$, et al. Detection of triploid, molar, and vanishing twin pregnancies by a single-nucleotide polymorphism-based noninvasive prenatal test. Am J Obstet Gynecol. 2015;212(1):79.e71-9.

32. Choi H, Lau TK, Jiang FM, et al. Fetal aneuploidy screening by maternal plasma DNA sequencing: 'false positive' due to confined placental mosaicism. Prenat Diagn. 2013;33(2):198-200.

33. Hall AL, Drendel HM, Verbrugge $J$, et al. Positive cell-free fetal DNA testing for trisomy 13 reveals confined placental mosaicism. Genet Med. 2013;15(9):729-32
34. Dong HC, Lee J, Jeon YJ, et al. A case of maternal uniparental disomy of chromosome 20 detected by noninvasive prenatal test of 1,000 high-risk pregnancies. J Genet Med. 2017;14(1):31-33.

35. Mardy A. Wapner RJ confined placental mosaicism and its impact on confirmation of NIPT results. Am J Med Genet C Semin Med Genet. 2016; 172(2):118-22.

36. Benn P, Cuckle H. Pergament E non-invasive prenatal testing for aneuploidy: current status and future prospects. Ultrasound Obstet Gynecol. 2013;42(1):15.

\section{Ready to submit your research? Choose BMC and benefit from:}

- fast, convenient online submission

- thorough peer review by experienced researchers in your field

- rapid publication on acceptance

- support for research data, including large and complex data types

- gold Open Access which fosters wider collaboration and increased citations

- maximum visibility for your research: over $100 \mathrm{M}$ website views per year

At $\mathrm{BMC}$, research is always in progress.

Learn more biomedcentral.com/submissions 